\title{
Etiology and Predisposing Factors for Electrical Current Injury in Children
}

\author{
Muhammad Kashif Bashir* Muhammad Sharif, Aisha Javeed, Aisha Ishtiaq, Sadaf Abbas \\ Department of Pediatric Surgery, King Edward Medical University, Mayo Hospital Lahore, Pakistan.
}

\begin{abstract}
Aims and Objectives: To analyze the data regarding etiological and predisposing factors in pediatric burns and make conclusion for prevention of pediatric burns.
\end{abstract}

Study design: Retrospective hospital based observational study.

Setting: Department of Pediatric Surgery, King Edward Medical University, Mayo Hospital Lahore.

Duration of Study: From June 2017 to June 2018.

Methodology: Children with electric current injuries were admitted in Pediatric Surgery Department, King Edward Medical University, Mayo Hospital, Lahore. As it was a retrospective study so the main source of information was the hospital admission files. A detailed research proforma was made having all variables and data was collected. Data regarding total number of patients, age, gender, mechanism of burn injury, operating findings, treatment and outcome were noted and statistical analysis was done by using SPSS version 20.

Results: One hundred and thirty $(\mathrm{n}=130)$ patients with burn injuries caused by electric current in age ranging from 2 to 12 years were treated during one year period. There were 72(55\%) males and 58(45\%) females. Areas involved were mainly the limbs and face. High voltage electric current was responsible for $90(69 \%)$ burn cases and low voltage in 40(31\%) cases. Electric current injury caused by direct contact occurred in $100(77 \%)$ cases whereas electric flash burn was responsible in 30(23\%) cases. Fasciotomy was performed in $78(60 \%)$ cases amputations at different levels in 24(18\%) and disarticulations of shoulder joint were performed in $6(4.5 \%)$ cases. Split thickness skin grafting was done in $80(61.5 \%)$ cases whereas $12(9 \%)$ cases having minor injury were treated conservatively. 92(71\%) cases were discharged home, 23(17.5\%) cases expired and in $15(11.5 \%)$ cases parents refused for treatment.

Conclusion: Burns are caused by human errors and are therefore preventable. Disability due to severe burn adversely affects the life of a growing child and is a huge social issue. Public awareness through print and electronic media as well as education at school level is to be stressed in order to prevent electric current burn injury resulting in high morbidity and mortality. There is a need to establish more state of the art pediatric burn units according to population consensus in our country.

Keywords: Electric current, Burn injuries, Predisposing factors, Etiology, Management, Epidemiology, Outcome.

\section{INTRODUCTION}

Burn injury can be caused by heat, electricity, chemicals, light, radiation and friction [1]. Burn trauma continued to be a major cause of high mortality and morbidity in children in developing countries [2-4]. Electric current injuries are contributing significantly to overall trauma caused by burns [5]. These are potentially devastating form of multisystem injuries [6, 7]. According to American Burns Association Report 2011, cases of electric burn injuries constituted 4.09\% of all over burn trauma [8]. Approximately, 20\% of total electric current burn injuries occur in children [9]. Most electrical injuries that occur in children are at home, with extension leads [10].

Burn injuries due to electric current remain a complex surgical challenge. Although with advances in intensive care unit, especially burn care has improved its outcome but

*Address correspondence to this author at the Department of Pediatric Surgery, King Edward Medical University, Mayo Hospital Lahore, Pakistan. E-mail: : kashif.paeds.surgeon@gmail.com prevention is still the best way of minimizing the prevalence and severity of electric current burn injuries [11-13].

\section{MATERIAL AND METHODS}

This study was conducted in department of Pediatric Surgery, King Edward Medical University, Mayo Hospital Lahore from June 2017 to June 2018. During study period a total of 1880 patients with burn trauma were presented in our emergency department. Out of 1880 patients, 990(52.6\%) were admitted and remaining 890(47.3\%) patients were either of minor burn injury or parents refused admission. Out of 990 burn patients, scald burn was 763(77\%), electric current burn $130(13 \%)$, flame burn $90(9 \%)$ and chemical burn was $0.7(1.1 \%)$. Data on demographic information, type of burn injury, treatment, complications and outcome was collected and analyzed.

\section{RESULTS}

One hundred and thirty $(n=130)$ burn patients due to electric 
current injury in age range from 2 to 12 years were treated during study period. There were $72(55 \%)$ males and 58(45\%) females (Fig. 1).

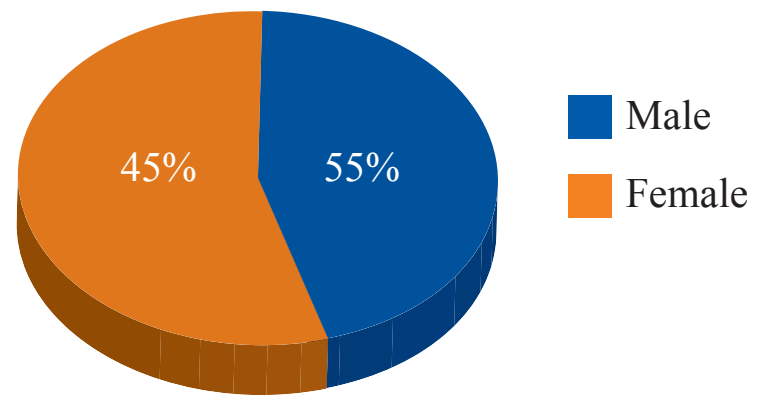

Fig. (1). Pie Chart Showing Gender Distribution.

$38(29 \%)$ patients were in age range of 2 to 5 years, $67(52 \%)$ in age range of 6-10 years and 25(19\%) were in age range of 11-12 years (Fig. 2).

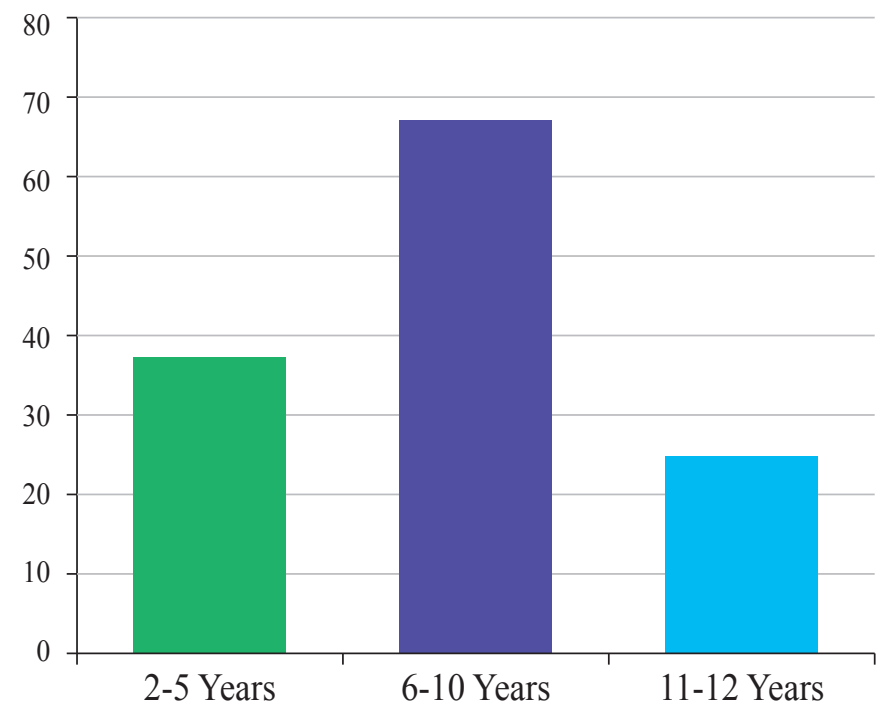

Fig. (2). Distribution of Patients according to Age in Years.

Surface area involved was mainly the limbs and face. In $90(69 \%)$ cases burn injury was due to high voltage electric current whereas low voltage electric current was responsible for burn injury in $40(31 \%)$ cases. $100(77 \%)$ patients had burn injury due to direct contact of any part of body with electric current source whereas electric flash burn was responsible in $30(23 \%)$ cases. Fasciotomy was performed in $78(60 \%)$ cases, amputations at different levels (above elbow in 8 cases, below elbow in 12 cases and below knee in 4 cases) in 24(18\%) cases and disarticulation of shoulder joint was performed in $6(4.5 \%)$ cases. Split thickness skin grafting was done in $80(61.5 \%)$ cases whereas $12(9 \%)$ cases were managed conservatively. 92(71\%) cases were discharged, 23 cases $(17.5 \%)$ expired and in $15(11.5 \%)$ cases parents refused for treatment (Table 1).
Table 1. Outcome of Patients.

\begin{tabular}{|l|c|c|}
\hline Outcome & No. of patients & \%age \\
\hline Fasciotomy & 78 & 60 \\
\hline Amputations & 24 & 18 \\
\hline Shoulder disarticulation & 6 & 4.5 \\
\hline Skin grafting & 80 & 61.5 \\
\hline Managed conservative & 12 & 9 \\
\hline Discharged & 92 & 71 \\
\hline Expired & 23 & 17.5 \\
\hline LAMA & 15 & 11.5 \\
\hline Total & 130 & 100 \\
\hline
\end{tabular}

\section{DISCUSSION}

Burn injuries due to electric current in pediatric population are very common in Pakistan. In this study it is noted that the most common age group involved in electric current injury was between 6 to 10 years followed by 2 to 5 years. This is comparable with study conducted in the Burns Centre Civil Hospital Karachi which showed that most common pediatric age group affected with electric current burn injury ranges from 5 to 10 years [14]. It is also noted that male children are predominantly affected with electric current injury than female children. Same finding is also noted in other local as well as international studies [15-17].

In our study main cause of electric current burn is high voltage followed by low voltage electric current. Same was also noted in other national and international studies $[18,19]$. According to a national study by Razzak JA, et al. majority of electric current trauma is caused by high voltage electric current [20].

When retrospective detailed history was taken it was came to know that high voltage electric current wires are passing in front of residential buildings and people dry their wet clothes on their balconies and accidently they can come in contact with them. Similarly children playing on these balconies can have electric current burn injuries due to direct contact of their body or by use of some metallic rods through which electric current can pass very easily like wipers. In some areas instead of strict legislations there is kite flying and string used for kite flying is usually made up of metallic materials like nylon, silk or wire which acts as good conductor for electricity and children try to retrieve kites enmeshed in live electric wires at the cost of their life. We are receiving these patients not only from Lahore but outside from Lahore.

\section{CONCLUSION}

Electric current burn injury is caused by human errors and is one of the significant causes for disability. Disability due to severe electric burn adversely affects the life of a growing 
child and is a huge social dilemma.

\section{RECOMMENDATIONS}

- Education for prevention of electric injuries through social and mobile media.

- Teaching first aid and preventive measures at school level.

- Main street wires should be at a safe distance from residential buildings.

- Legislation and strict implementation of law regarding kite flying.

- Making power points child proof and should be at higher level from ground.

- Need to establish more pediatric burn units.

\section{CONFLICT OF INTEREST}

Declared none.

\section{ACKNOWLEDGEMENTS}

Declared none.

\section{REFERENCES}

[1] Herndon DN. Total Burn Care. $3^{\text {rd }}$ ed. USA: Elsevier Saunders 2007.

[2] Subrahmanyon M. Electrical Burn injuries. Ann Medit Burns 2004; $17: 1-5$.

[3] Gupta M, Gupta OK, Yaduvanshi RK, Upadhyaya J. Burn epidemiology: The pink scene. Burns 1993; 19: 47-51

DOI: 10.1016/0305-4179(93)90100-M

[4] Haberal M, Ucar N, Bilgin N. Epidemiological survey of burns treated in Ankara. Turkey and desirable burn prevention strategies. Burns 1995; 21(6): 601-6.

DOI: 10.1016/0305-4179(95)00044-C

[5] Forjuoh SN. Burns in low- and middle- income countries: A review of available literature on descriptive epidemiology, risk factors, treatment and prevention. Burns 2006; 32: 529.

DOI: 10.1016/j.burns.2006.04.002

[6] Subrahmanyam M. Electrical burn injuries. Ann Burns Fire Disasters 2004; 17: 9-11.

[7] El-Gallal ARS, Yousef SM. Electrical burns in Benghazi urban area. Ann Burns Fire Disasters 1998, 9: 198-202.

[8] American Burns Association. National Burns Repository report. Dataset version 7.0. 2017; Available at: www.ameriburns.og

[9] Rai J, Jeschke MG, Barrow RE, et al. Electrical injuries: A 30-year review. J Trauma 1999; 46: 933-6.

DOI: 10.1097/00005373-199905000-00026

[10] Baker MD, Chiaviello C. Household electrical injuries in children. Epidemiology and identification of avoidable hazards. Am J Dis Child 1989; 143(1): 59-62.

DOI: 10.1001/archpedi.1989.02150130069017

[11] Burn Injury Facts Report \# 86-1-2006. USA: SHARP 2006.

[12] Docking P. Electric burn injuries. Accid Emerg Nurs 1999; 7(2): 70-6. DOI: 10.1016/S0965-2302(99)80024-1

[13] Orgill DP, Pribaz JJ. Functional reconstruction following electrical injury. Ann N Y Acad Sci 1999; 886: 96-104. DOI: 10.1111/j.1749-6632.1999.tb07945.x

[14] Rabban J, Adler J, Rosen C, Blair J, Sheridan R. Electrical injury from subway third rails: Serious injury associated with intermediate voltage contact. Burns 1997; 23(6): 515-8. DOI: $10.1016 / \mathrm{S} 0305-4179(97) 00033-8$

[15] Mago V, Yaseen M, Bariar LM. Epidemiology and mortality of burns in JNMC Hospital, AMU Aligarh: A 5 years study. Indian J Commun 2004; 29(4): 18.

[16] Kypri K, Chalmers DJ, Langley JD, Wright CS. Child injury morbidity in New Zealand, 1987-1996. J Paediatr Child Health 2001; 37: 227-34. DOI: 10.1046/j.1440-1754.2001.00668.x

[17] Schubert W, Arhenholz DH, Solem LD. Burns from hot oil and grease: A public health hazard. J Burn Care Rehabil 1990; 11: 558-62. DOI: 10.1097/00004630-199011000-00014

[18] Alden NE, Rabbitts A, Yurt RW. Contact burns: Is further prevention necessary? J Burn Care Res 2006; 27: 472-5. DOI: 10.1097/01.BCR.0000226102.43343.0A

[19] Kenardy JA, Spence SH, Macleod AC. Screening for posttraumatic stress disorder in children after accidental injury. Pediatrics 2006; 118: 1002-9. DOI: 10.1542/peds.2006-0406

[20] Razzak JA, Luby SP, Laflamme L, Chotani H. Injuries among children in Karachi, Pakistan --what, where and how. Public Health 2004; 118: 114-20.

DOI: 10.1016/S0033-3506(03)00147-1 